\title{
COMUNICAÇÃO
}

\section{COMPORTAMENTO DO ALGODOEIRO CULTIVAR DELTA OPAL SOB ESTRESSE HÍDRICO COM E SEM APLICAÇÃO DE BIOESTIMULANTE}

\author{
Cotton plant cultivar delta opal behavior under water stress with or without biostimulant
}

\author{
Roberto Baldo ${ }^{1}$, Silvana de Paula Quintão Scalon ${ }^{2}$, Yara Brito Chaim Jardim Rosa ${ }^{3}$, \\ Rosilda Mara Mussury ${ }^{4}$, Roseli Betoni ${ }^{5}$, Willian dos Santos Barreto ${ }^{6}$
}

\begin{abstract}
Resumo
Objetivou-se, com esse trabalho, avaliar o efeito do bioestimulante Stimulate®, aplicado ou não em diferentes fases do desenvolvimento do algodoeiro cv. Delta Opal, (Gossypium hirsutum L.) cultivado em casa de vegetação e submetido ou não ao estresse hídrico. Foram aplicados 25, 60 e 100\% do volume total de poros (VTP) preenchidos com água e o Stimulate ${ }^{\circledR}$ aplicado na semente, na semente e na fase de botão floral e sem a aplicação do bioestimulante, aos 69 dias após a semeadura. A duração do estresse hídrico foi de 15, 30 e 45 dias após a aplicação do estresse hídrico. O algodoeiro cv Delta Opal não tolerou deficiência hídrica de 25\% VTP iniciado na fase de botão floral, sendo observadas as menores alturas, diâmetros de colo, número de folhas, e comprometendo também a formação de estruturas reprodutivas. O bioestimulante na dose e na forma aplicada não proporcionou melhoras no desenvolvimento das plantas quando submetidas à falta de água, já em plantas submetidas ao excesso de água, houve aumento do diâmetro do colo das plantas.
\end{abstract}

Termos para indexação: Ecofisiologia, algodão, fitorreguladores, Gossypium hirsutum.

\begin{abstract}
This work was aimed at evaluating the effect of biostimulant Stimulate ${ }^{\circledR}$ applied or not at different development stages of cotton plant cv Delta Opal, (Gossypium hirsutum L.) cultivated in greenhouse, subjected or not to water stress. Applications of 25, 60 and $100 \%$ of total volume of pores (VTP) filled up with water were conducted, and then Stimulate ${ }^{\circledR}$ was sprinkled over the seed and on the flower bud stage, without biostimulant application 69 days after sowing. The water stress time period was that of 15,30 and 45 days after water stress application. The cotton plant cv Delta Opal did not tolerate hydric deficit of 25\% VTP on the flower bud set off, where smaller heights as well as smaller colon diameters and flower number were observed, all of which also endanger reproductive structure formation. The use of biostimulant on the dosage and the type of application did not render any improvement on plant development when submitted to lack of water; nevertheless there was a colon diameter increase on plants subjected to water excess.
\end{abstract}

Index terms: Ecophysiology, cotton plant, plant regulators, Gossypium hirsutum.

(Recebido em 20 de fevereiro de 2008 e aprovado em 1 de julho de 2008)

A necessidade hídrica das culturas condiciona as atividades fisiológicas e metabólicas das plantas. Quanto maior a disponibilidade de água no solo melhor a capacidade de absorção de nutrientes pelas raízes e maior a eficiência fotossintética, resultando em um máximo rendimento agrícola (AZEVEDO et al., 1993).
As respostas da célula ao estresse hídrico incluem mudanças no ciclo e divisões celulares, mudanças no sistema de endomembranas e vacuolização, bem como alterações na arquitetura da parede celular. Em relação ao metabolismo, ocorre a produção de substâncias osmorreguladoras, o que vai favorecer a planta em casos de falta de água (TAIZ \& ZEIGER, 2004).

\footnotetext{
'Engenheiro Agrônomo, Mestre - Rua Domingos de Lima, 220, apto 31 - 78740-225 - Rondonópolis, MT - robertobaldoigt@hotmail.com Bióloga, Doutora em Ciência dos Alimentos - Faculdade de Ciências Agrárias/FCA - Universidade Federal da Grande Dourados/UFGD - Rodovia Dourados-Itahum, Km 12 - 79804-970 - Dourados, MS - silvana.scalon@ufgd.edu.br

${ }^{3}$ Engenheira Agrônoma, Doutora em Agronomia - Faculdade de Ciências Agrárias/FCA - Universidade Federal da Grande Dourados/UFGD - Rodovia Dourados-Itahum, Km 12 - 79804-970 - Dourados, MS - yararosa@ufgd.edu.br

${ }^{4}$ Bióloga, Doutora - Faculdade de Ciências Biológicas e Ambientais/FCBA - Universidade Federal da Grande Dourados/UFGD - Rua Antônio de Carvalho 2620, BNH 3 plano - 79800-000 - Dourados, MS - mara.mussury@ufgd.edu.br

${ }^{5}$ Bióloga, Mestranda em Produção Vegetal - Departamento de Ciências Agrárias - Universidade Federal da Grande Dourados/UFGD - Rua Constituição, 1180 - New Jersey - Nossa Senhora da Abadia - 38022-130 - Uberaba, MG - roselibetoni@yahoo.com.br

${ }^{6}$ Graduando em Agronomia - Faculdade de Ciências Agrárias/FCA - Universidade Federal da Grande Dourados/UFGD - Rodovia Dourados-Itahum, Km 12 -79804-970 - Dourados, MS - williandosantos@bol.com.br
} 
Tanto a deficiência quanto o excesso de água nas plantas podem provocar profundas alterações no seu metabolismo, reduzindo o crescimento e o desenvolvimento e, consequentemente, influenciando no rendimento econômico da planta e na produção de fibras e sementes (BELTRÃO et al., 1997).

$\mathrm{O}$ algodoeiro necessita de uma maior quantidade de água, pouco antes e durante a fase de primeiro botão floral (REICHARDT, 1990). A deficiência hídrica reduz o desenvolvimento dessa planta, podendo até interrompêlo, ocasiona a queda de flores e frutos, e encurtamento das fibras (PASSOS et al., 1987).

Além da água, fatores endógenos como os hormônios, também influenciam o crescimento e o desenvolvimento das plantas. Assim, os biorreguladores e bioestimulantes favorecem o crescimento mais harmonioso com o desenvolvimento voltado para a maior produção e melhor qualidade final das culturas (LAMAS, 2001).

Bioestimulantes vegetais são combinações de biorreguladores ou de biorreguladores e outras substâncias que, aplicadas exogenamente, possuem ações similares aos grupos de hormônios vegetais conhecidos (CASTRO \& VIEIRA, 2001; LAMAS, 2001).

O Stimulate ${ }^{\circledR}$ é um bioestimulante que contém três reguladores de crescimento em sua composição. O ácido indolbutírico $(0,0005 \%)$, o qual é transformado pelo metabolismo da planta em AIA (ácido indolacético), uma auxina que estimula o alongamento celular; a cinetina $(0,009 \%)$ que atua na divisão celular e o ácido giberélico $(0,005 \%)$ que atua em diversos passos do metabolismo das plantas, inclusive no processo de germinação das sementes (LIMA et al., 2003).

$\mathrm{Na}$ maioria dos estudos com o algodoeiro tem-se, até o presente, pesquisado os efeitos do excesso ou da deficiência temporária de água no solo sem a verificação simultânea de fatores que podem interferir na capacidade dessa cultura resistir a esse tipo de estresse. Entre os fatores destacam-se o período de duração do estresse, o estágio de desenvolvimento das plantas, a cultivar, as estratégias fisiológicas para resistência ao estresse e a aplicação ou não de bioreguladores capazes de minimizar os efeitos danosos à planta.

Objetivou-se, com este trabalho, estudar os efeitos de diferentes períodos de duração do estresse hídrico e da aplicação de bioestimulante em diferentes fases do desenvolvimento do algodoeiro cv. Delta Opal.

$\mathrm{O}$ experimento foi realizado em casa de vegetação da Universidade Federal da Grande Dourados, Dourados MS, localizada na latitude de $22^{\circ} 13^{\prime} 16^{\prime \prime S}$, longitude $54^{\circ} 17^{\prime} 01^{\prime \prime} \mathrm{W}$ e altitude de $430 \mathrm{~m}$. Como substrato utilizou- se o Latossolo Vermelho distroférrico, peneirado em peneira de malha $0,5 \mathrm{~cm}$ e seco em condição ambiente.

A planta utilizada, Gossypium hirsutum cultivar Delta Opal, foi semeada diretamente em vasos com, 4,5 kg de solo, sendo cinco sementes por vaso, e aos 15 dias após emergência foi realizado o desbaste, deixando uma planta por vaso.

Os tratamentos foram constituídos de três fatores em três níveis. O primeiro fator foram as três formas de aplicação do bioestimulante Stimulate $®$, o segundo fator foram os três níveis de estresse hídrico e o terceiro fator foram as três épocas de avaliação do estresse hídrico.

Bioestimulante: foi aplicado diretamente na semente no dia da semeadura, na semente e na fase de botão floral, via foliar, aos 69 dias após a semeadura e a testemunha que não recebeu qualquer tipo de aplicação.

Foram utilizados $25 \mathrm{~mL}$ de bioestimulante para cada $500 \mathrm{~g}$ de sementes aplicados por meio de pipeta volumétrica . As sementes, acondicionadas em sacos de polietileno transparentes com capacidade para dois quilos, receberam o bioestimulante e foram homogeneizadas manualmente mediante agitação por dois minutos. As sementes que não receberam o tratamento com o Stimulate $®$ passaram pelo mesmo processo, mas com aplicação do mesmo volume de água destilada. Uma hora depois as sementes foram semeadas nos vasos.

Para a aplicação foliar no início da fase de botão floral, utilizou-se um pulverizador costal de $\mathrm{CO}_{2}$, com pressão de $40 \mathrm{lib} \mathrm{pol}^{-2}$, com barra dotada com um bicoleque 110:02 VS Teejet, com volume de aplicação utilizado de $300 \mathrm{~L} \mathrm{ha}^{-1}$, na dosagem de $250 \mathrm{~mL} \mathrm{ha}^{-1}$ do bioestimulante.

Estresse hídrico: Até os 69 dias após a emergência todas as plantas foram irrigadas com $60 \%$ do volume total de poros preenchidos com água. $\mathrm{O}$ volume total de poros do solo foi calculado segundo Embrapa (1997), a partir dos valores de densidade aparente (Da) e densidade de partículas $(\mathrm{Dp})$, utilizando-se a seguinte fórmula: $V T P=[(D p$ - Da)/Dp ] x 100. A irrigação foi feita diariamente pesandose o conjunto vaso-solo-planta e colocando-se a quantidade necessária de água para cada tratamento em questão.

Aos 69 dias após a semeadura foram utilizados (por um período de 45 dias) 25, 60 e 100\% do volume total de poros preenchidos com água para caracterizar deficiência hídrica, sem estresse hídrico e excesso de água, respectivamente.

Durante o período de estresse hídrico, as plantas foram avaliadas quinzenalmente (aos 84, 99 e 114 dias após a semeadura) quanto à altura (compreendida entre a superfície do solo e a inserção da última folha), diâmetro do colo com auxílio de paquímetro digital (medida obtida no colo das plantas), número de folhas; área foliar, mensurada com um integrador de área foliar; massa fresca de parte aérea, massa fresca de raiz, massa seca da parte aérea e massa seca 
de raiz. Aos 114 dias após semeadura, foi avaliado o número, diâmetro e peso médio de maçãs por planta. Para os estudos morfológicos do sistema radicular e para a avaliação da parte aérea e do sistema radicular as plantas foram removidas do substrato e separadas, por meio de tesoura de poda, em parte aérea e sistema radícular.

A parte aérea foi pesada, em seguida as folhas foram retiradas para a avaliação de área foliar. O sistema radicular foi lavado para separação do solo com auxílio de uma peneira de malha de $0,5 \mathrm{~mm}$ e logo em seguida pesado. Para obtenção das massas secas, o material identificado foi acondicionado em estufa a $65^{\circ} \mathrm{C}$, com circulação de ar, durante 72 horas, até peso constante.

As ilustrações dos sistemas radiculares para estudos morfológicos foram realizadas com auxílio de máquina Sony Cyber Shot 6.0, para identificação das estruturas formadas com a indução do estresse.

$\mathrm{O}$ delineamento experimental utilizado foi o inteiramente casualizado em esquema fatorial $3 \times 3 \times 3$, com quatro repetições de cinco vasos com uma planta cada.

Consideraram os fatores estudados como qualitativos e os dados obtidos foram submetidos à análise de variância, e posteriormente as médias foram comparadas pelo teste Tukey, a 5\% de probabilidade (BANZATO \& KRONKA, 1989).

A altura e o diâmetro do colo foram menores sob deficiência hídrica (25\% do VTP) Quando houve excesso de água (100\% VTP) sem aplicação do Stimulate ${ }^{\circledR}$ e com Stimulate® aplicado na semente e na fase de botão floral, foram observadas as maiores alturas das plantas (Tabela 1). Os dados de altura de planta observados na presente pesquisa encontram-se na faixa daqueles observados por Nagashima et al., (2007) avaliando o efeito da aplicação ou não de cloreto de mepiquat.

Em relação ao diâmetro de colo, os maiores valores foram observados nos tratamentos com excesso de água ( $100 \%$ VTP) e com aplicação de Stimulate ${ }^{\circledR}$ só na semente e na semente e na fase de botão floral. Os menores valores de diâmetro do colo das plantas de algodão, foram observados no tratamento de deficiência de água ( $25 \%$ do VTP), mostrando que, em casos de falta de água, o crescimento secundário do caule diminui, reduzindo o diâmetro.

Esses resultados foram semelhantes também aos observados por Almeida et al. (1992), trabalhando com estresse anoxítico do meio edáfico com as variedades de algodão CNPA Precoce1 e CNPA 3H, no qual as plantas submetidas ao estresse anoxítico na fase de floração apresentaram maiores alturas que os demais tratamentos. Entretanto, Beltrão et al. (1997) em algodoeiro CNPA acala 1, não observou diferença de diâmetro, quando submetido somente a excesso de água. $\mathrm{O}$ aumento do diâmetro, na cultivar Delta Opal, pode ter sido influenciado pela aplicação do bioestimulante, que, juntamente com o excesso de água, influenciou na maior produção de etileno. Esse hormônio pode ser sintetizado em maior quantidade pela planta, devido a interação dos três tipos de hormônios (auxina, giberelina e citocinina) presentes na composição do bioestimulante, que, aplicado exogenamente, pode influenciar na sua maior síntese internamente, o que está de acordo com Taiz \& Zeiger (2004).

O Stimulate ${ }^{\circledR}$ não proporcionou incremento de crescimento das plantas quando essas sofreram deficiência hídrica, em geral sua aplicação causou redução do crescimento, o que não ocorreu para as características, altura e diâmetro quando se aplicou o tratamento de excesso de água de $100 \%$ do VTP. Esses resultados diferem de informações da literatura para outras espécies como por exemplo dos resultados de Prado-Neto et al., (2007) que observaram resultados significativos quando préembeberam sementes de (Genipa americana L.) por doze horas em Stimulate ${ }^{\circledR}\left(10 \mathrm{ml} \mathrm{L}^{-1}\right)$ proporcionando maiores índices de velocidade de germinação e também maior comprimento total e das raízes das plântulas de jenipapo em relação aos demais tratamentos.

Os menores valores de massa fresca da parte aérea ocorreram quando houve deficiência de água (Tabela 2),

Tabela 1 - Valores médios de altura e diâmetro de colo das plantas de algodão cv Delta Opal, em função da água e do Stimulate®.

\begin{tabular}{|c|c|c|c|c|c|c|}
\hline \multirow[b]{3}{*}{ Stimulate $®$} & \multicolumn{6}{|c|}{ Água } \\
\hline & \multicolumn{3}{|c|}{ Altura $(\mathrm{cm})$} & \multicolumn{3}{|c|}{ Diâmetro (mm) } \\
\hline & $25 \%$ & $60 \%$ & $100 \%$ & $25 \%$ & $60 \%$ & $100 \%$ \\
\hline Ausência & $78,75 \mathrm{Ba}$ & $95,00 \mathrm{Aa}$ & $101,83 \mathrm{Aa}$ & 7,15 Ba & 8,54 Aab & $8,67 \mathrm{Ab}$ \\
\hline Semente & $73,66 \mathrm{Ba}$ & 93,79 Аа & $89,54 \mathrm{Ab}$ & 7,77 Ba & $8,00 \mathrm{Bb}$ & $9,58 \mathrm{Aa}$ \\
\hline $\begin{array}{l}\text { Semente e } \\
\text { Botão }\end{array}$ & $76,62 \mathrm{Ba}$ & $83,52 \mathrm{Bb}$ & 96,58 Aab & 7,36 Ba & 8,90 Аа & 9,35 Aab \\
\hline $\mathrm{CV}(\%)$ & & 11,23 & & & 10,27 & \\
\hline
\end{tabular}


mostrando que, quando submetidas a essa situação, ocorrem modificações intensas nas plantas que se refletem no crescimento e no desenvolvimento vegetal.

Os menores valores de massa fresca de raiz e o menor número de raízes (Figura 1: A, D, G), também foram observados quando houve deficiência de água.

A diminuição das massas fresca e seca da parte aérea aos 45 dias após a aplicação dos tratamentos, pode ser explicada baseada no fato da planta já estar completando seu ciclo e entrando na fase maturidade plena, o que acarretou em uma perda de folhas. Observou-se que, com a deficiência hídrica, estas características foram significantemente menores (Tabelas 2 e 3 ), uma vez que a falta de água também induz à abscisão foliar e diminuição da superfície foliar das plantas, concordando com informações da literatura (KERBAUY, 2004; TAIZ \& ZEIGER, 2004).

Os maiores valores de massa seca da parte aérea foram observados sob 60\% e 100\% do VTP, com água aos 30 dias após aplicação dos tratamentos (Tabela 3).

O menor valor ocorreu com deficiência de água e aos 45 dias, isso ocorreu provavelmente devido a pouca disponibilidade de água ter diminuído o acúmulo de fotoassimilados e que o período correspondente aos 45 dias após iniciar os tratamentos, normalmente os fotoassimilados já estavam sendo destinados para as estruturas reprodutivas. Os dados de massa seca da parte aérea observados na presente pesquisa encontram-se bem abaixo daqueles observados por Nagashima et al., (2007) tanto nas plantas tratadas com regulador de crescimento quanto naquelas sem o tratamento, provavelmente as condições de cultivo em cada de vegetação na presente pesquisa tenham prejudicado a produção de fotoassimilados.

O maior valor de massa seca de raiz (Tabela 3) e o maior número de raízes (Fig 1: C, F, I) foram observados com $100 \%$ do VTP com água, aos 45 dias de iniciado os tratamentos.

Visualmente, a maior parte das raízes secundárias e terciárias se concentravam na parte superior do vaso, região mais arejada do solo, uma vez que essas raízes são responsáveis pela absorção de água, minerais e do oxigênio molecular. Resultados semelhantes foram encontrados por Almeida et al. (1992), que trabalhando com encharcamento do meio edáfico, observou uma maior quantidade de raízes de algodoeiro cultivar CNPA Precoce 1, na superfície do solo. Isso favoreceu a planta durante o período de estresse.

Observou-se que, após 15 dias de iniciada a deficiência hídrica (25\% VTP), o sistema radicular já estava menos desenvolvido quando se compara com os outros níveis de água. Embora a parte aérea apresente redução sob

Tabela 2 - Valores médios de massa fresca de parte aérea (MFPA) e massa fresca de raiz (MFR) de plantas de algodão cv Delta Opal, em função da água e do tempo de duração do estresse.

\begin{tabular}{cccccccc}
\hline & \multicolumn{3}{c}{ MFPA $\left(\mathrm{g} \mathrm{planta}^{-1}\right)$} & & \multicolumn{3}{c}{ MFR $\left(\mathrm{g} \mathrm{planta}^{-1}\right)$} \\
\cline { 2 - 4 } \cline { 6 - 8 } Tempo & $25 \%$ & $60 \%$ & $100 \%$ & & $25 \%$ & $60 \%$ & $100 \%$ \\
15 & $45,42 \mathrm{Ab}$ & $87,87 \mathrm{Aa}$ & $101,46 \mathrm{Aa}$ & & $10,85 \mathrm{Ab}$ & $11,86 \mathrm{Cb}$ & $18,38 \mathrm{Ba}$ \\
30 & $43,88 \mathrm{Ac}$ & $95,65 \mathrm{Ab}$ & $112,87 \mathrm{Aa}$ & & $11,31 \mathrm{Ab}$ & $18,73 \mathrm{Ba}$ & $20,25 \mathrm{Ba}$ \\
45 & $35,45 \mathrm{Ac}$ & $60,90 \mathrm{Bb}$ & $86,41 \mathrm{Ba}$ & & $12,25 \mathrm{Ab}$ & $24,82 \mathrm{Aa}$ & $29,70 \mathrm{Aa}$ \\
$\mathrm{CV}(\%)$ & & 19,12 & & & & 30,63 & \\
\hline
\end{tabular}

Médias seguidas de letras maiúsculas na coluna e minúsculas na linha não diferem entre si pelo teste de Tukey, a 5\% de probabilidade. DAT: Dias após iniciar os tratamentos.

Tabela 3 - Valores médios de massa seca de parte aérea (MSPA) e massa seca de raiz (MSR) de algodoeiro, cv Delta Opal, em função da água e do tempo de duração do estresse hídrico.

\begin{tabular}{|c|c|c|c|c|c|c|}
\hline \multirow[b]{2}{*}{ DAT } & \multicolumn{3}{|c|}{ MSPA (g planta-1) } & \multicolumn{3}{|c|}{ MSR (g planta-1) } \\
\hline & $25 \%$ & $60 \%$ & $100 \%$ & $25 \%$ & $60 \%$ & $100 \%$ \\
\hline 15 & $17,50 \mathrm{Bb}$ & $25,32 \mathrm{Ba}$ & $28,95 \mathrm{Ba}$ & $2,04 \mathrm{Ba}$ & $2,23 \mathrm{Ca}$ & $2,83 \mathrm{Ba}$ \\
\hline 30 & $23,44 \mathrm{Ab}$ & $40,76 \mathrm{Aa}$ & $43,25 \mathrm{Aa}$ & $2,00 \mathrm{Bb}$ & $3,28 \mathrm{Ba}$ & 3,44 Ba \\
\hline 45 & $13,08 \mathrm{Bc}$ & $21,72 \mathrm{Bb}$ & $30,60 \mathrm{Ba}$ & $3,24 \mathrm{Ac}$ & $4,87 \mathrm{Ab}$ & 5,68 Aa \\
\hline $\mathrm{CV}(\%)$ & & 18,74 & & & 24,83 & \\
\hline
\end{tabular}

Médias seguidas de mesmas letras maiúsculas na coluna e minúsculas na linha não diferem entre si pelo teste de Tukey, a 5\% de probabilidade. DAT: Dias após iniciar os tratamentos. 
deficiência de água (25\% VTP), nota-se que a massa seca da parte aérea aumentou até os 30 dias após o início dos tratamentos diminuindo em seguida, enquanto que o sistema radicular continuou crescendo ao longo das avaliações.

De maneira semelhante, em trabalho realizado por Anti et al. (2002) avaliando duas espécies selvagens de tomate sob deficiência hídrica, os autores constataram que a espécie Lycopersicon pennellii (Correal) D'Arcy, apresentou raízes muito finas e com volume extremamente reduzido e menores valores de massa fresca e seca.
O número de folhas e a área foliar não foram influenciados pela aplicação do Stimulate® (Tabela 5).

Em relação ao período de estresse, essas características foram menores aos 45 dias após a aplicação dos tratamentos, sendo os menores valores observados no tratamento de deficiência hídrica (25\% do VTP). De acordo com Taiz \& Zeiger (2004) uma vez que o crescimento foliar depende principalmente da expansão celular, a inibição dessa provoca uma lentidão da expansão foliar, no início do desenvolvimento da deficiência hídrica. Com área foliar
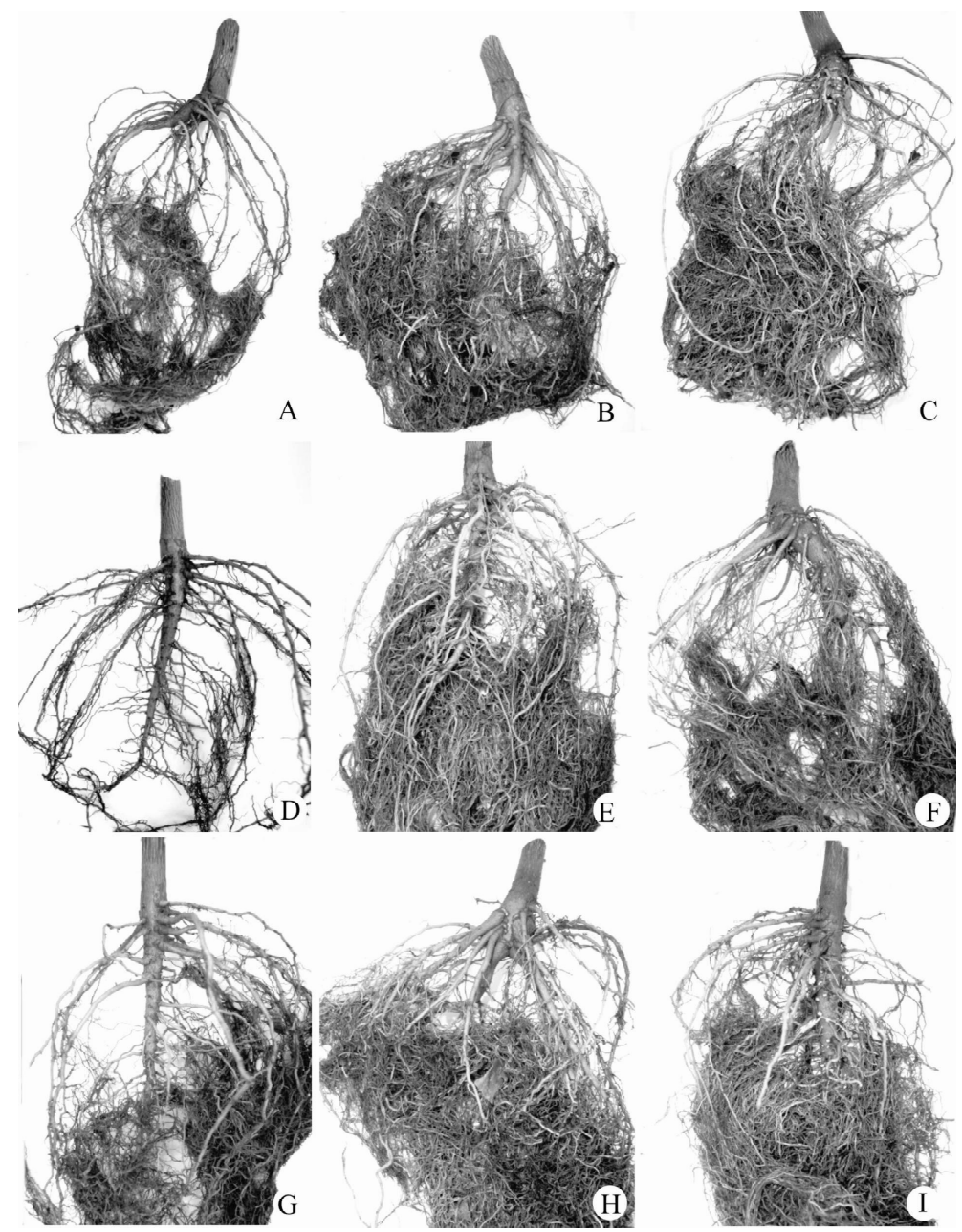

Figura 1 - Modificações morfológicas da raiz em função das diferentes disponibilidades de água em algodoeiro cv. Delta Opal, e aplicação ou não de Stimulate®. A. Planta com $25 \%$ VTP com água, sem Stimulate®; B. Planta com $60 \%$ VTP com água, sem Stimulate®; C. Planta com 100\% VTP com água, sem Stimulate®; D. Planta com 25\% do VTP com água, com Stimulate ${ }^{\circledR}$ na semente; E. Planta com $60 \%$ VTP com água, com Stimulate® na semente; F. Planta com 100\% VTP com água, com Stimulate® na semente; G. Planta com 25\% VTP com água, com Stimulate® na semente e no botão floral; H. Planta com $60 \%$ VTP com água, com Stimulate ${ }^{\circledR}$ na semente e no botão floral; I. Planta com 100\% VTP com água, com Stimulate ${ }^{\circledR}$ na semente e no botão floral. UFGD, Dourados, 2006. 
menor a planta transpira menos, conservando uma maior quantidade de água no solo e por um período mais longo.

A redução no número de folhas, pode ser justificada considerando que uma das alterações fisiológicas em relação ao estresse hídrico é a maior produção endógena de hormônios, como o ácido abscísico e o etileno, e na presença desses compostos há uma maior senescência e abscisão de folhas (LARCHER, 2000).

Conforme Santos \& Carlesso (1998) e Taiz \& Zeiger (2004), a resposta mais proeminente da maioria das plantas à deficiência hídrica, consiste no decréscimo da produção da área foliar, do fechamento dos estômatos, da aceleração da senescência e da abscisão das folhas. Quando as plantas são expostas a situações de deficiência de água, exibem freqüentemente, respostas fisiológicas que resultam, de modo indireto, na conservação da água no solo, o que gera economia de água para períodos posteriores, diminuindo a superfície transpiratória, no caso de perda de folhas, ou no simples fato de parar o crescimento foliar, reduzindo a área foliar e mantendo o peso da parte aérea.

De acordo com Marur (1999), um dos primeiros processos afetados pela deficiência hídrica é a expansão foliar, que vai depender da turgescência das células o que é regulado pelo ajuste osmótico. Segundo Kerbauy (2004) outra forma de ter a área foliar diminuída é através da redução do número de folhas, pois o estresse hídrico diminui o número e a taxa de crescimento dos ramos. Santos \& Carlesso (1998) ainda reforçam que a expansão celular é o processo fisiológico mais sensível ao déficit hídrico.

O Stimulate ${ }^{\circledR}$ não alterou o número de estruturas reprodutivas. Sob deficiência hídrica (25\% do VTP), ocorreu o menor número de maçãs, as menores massas por maçã e os menores diâmetros (tabela 6). Baseado nos resultados, sugere-se que a deficiência hídrica induzida na fase de botão floral prejudica significativamente a produção de estruturas reprodutivas dessa cultivar de algodão. Por isso, as plantas para sobreviverem em ambientes estressantes, não produzem o máximo que podem, ao contrário, elas têm que encontrar um equilíbrio entre rendimento e sobrevivência, o que está de acordo com Arruda et al. (2002) que sugerem que plantas que não são especializadas em desenvolverem-se em ambientes com deficiência hídrica, crescem vagarosamente e normalmente apresentam um porte pequeno. Essa estratégia permite à planta desenvolver-se em ambientes limitantes com restrições, mas utilizando ao máximo todos os recursos disponibilizados pelo ambiente.

Esses resultados corroboram informações da literatura nas quais o ambiente em que a planta está exposta afeta profundamente tanto a abscisão de folhas, quanto de estruturas reprodutivas (MCMICHAEL et al., 1973; OOSTERHUIS, 1992). A deficiência hídrica tem sido considerada um dos principais fatores ambientais que provocam a abscisão de estruturas reprodutivas em algodoeiro, justamente por causar acentuado estresse nas plantas (DOORENBOS \& KASSAM, 1994).

As plantas submetidas ao excesso de água (100\% VTP), apresentaram lenticelas na raiz principal desde a primeira avaliação, aos 15 dias após iniciar os tratamentos (Figura 2A), até a última avaliação, aos 45 dias após iniciar os tratamentos (Figura 2D).

Tabela 5 - Número de folhas por planta e área foliar de algodoeiro em função de dias que as plantas permaneceram em estresse, água e aplicação de Stimulate.

\begin{tabular}{|c|c|c|c|}
\hline \multirow{4}{*}{ Dias de Estresse } & & Número de Folhas/Planta & Área foliar $\mathrm{cm}^{2}$ \\
\hline & 15 & $43,22 \mathrm{a}$ & $1346,54 \mathrm{a}$ \\
\hline & 30 & $43,08 \mathrm{a}$ & $1317,06 \mathrm{a}$ \\
\hline & 45 & $35,52 \mathrm{~b}$ & $1055,62 \mathrm{~b}$ \\
\hline \multirow[t]{3}{*}{ Água } & $25 \%$ & $34,83 \mathrm{~b}$ & $620,88 \mathrm{c}$ \\
\hline & $60 \%$ & $41,30 \mathrm{a}$ & $1379,65 \mathrm{~b}$ \\
\hline & $100 \%$ & $45,69 \mathrm{a}$ & $1718,70 \mathrm{a}$ \\
\hline \multirow[t]{3}{*}{ Stimulate ${ }^{\circledR}$} & Ausência & $39,91 \mathrm{a}$ & $1282,10 \mathrm{a}$ \\
\hline & Semente & 39,19 a & $1203,91 \mathrm{a}$ \\
\hline & Semente e Botão & $42,72 \mathrm{a}$ & $1233,22 \mathrm{a}$ \\
\hline $\mathrm{CV}(\%)$ & & 20,48 & 25,05 \\
\hline
\end{tabular}

Médias seguidas de mesma letra na coluna não diferem entre si pelo teste de Tukey, a $5 \%$ de probabilidade. 
Tabela 6 - Massa, Diâmetro e Número de maçãs observados no final do período experimental, aos 45 dias após o início dos tratamentos, em função dos níveis de água estudados.

\begin{tabular}{cccc}
\hline Água & Diâmetro $(\mathrm{mm})$ & Peso (g maçãs por planta) & $\mathrm{N}^{\circ}$ (maçãs por planta) \\
\hline $25 \%$ & $4,01 \mathrm{~b}$ & $1,60 \mathrm{~b}$ & $0,66 \mathrm{~b}$ \\
$60 \%$ & $23,06 \mathrm{a}$ & $11,93 \mathrm{a}$ & $2,75 \mathrm{a}$ \\
$100 \%$ & $27,03 \mathrm{a}$ & $13,99 \mathrm{a}$ & $3,33 \mathrm{a}$ \\
$\mathrm{CV}(\%)$ & 12,23 & 11,35 & 9,81 \\
\hline
\end{tabular}

Médias seguidas de mesma letra na coluna não diferem significativamente entre si pelo teste de Tukey a 5\% de probabilidade
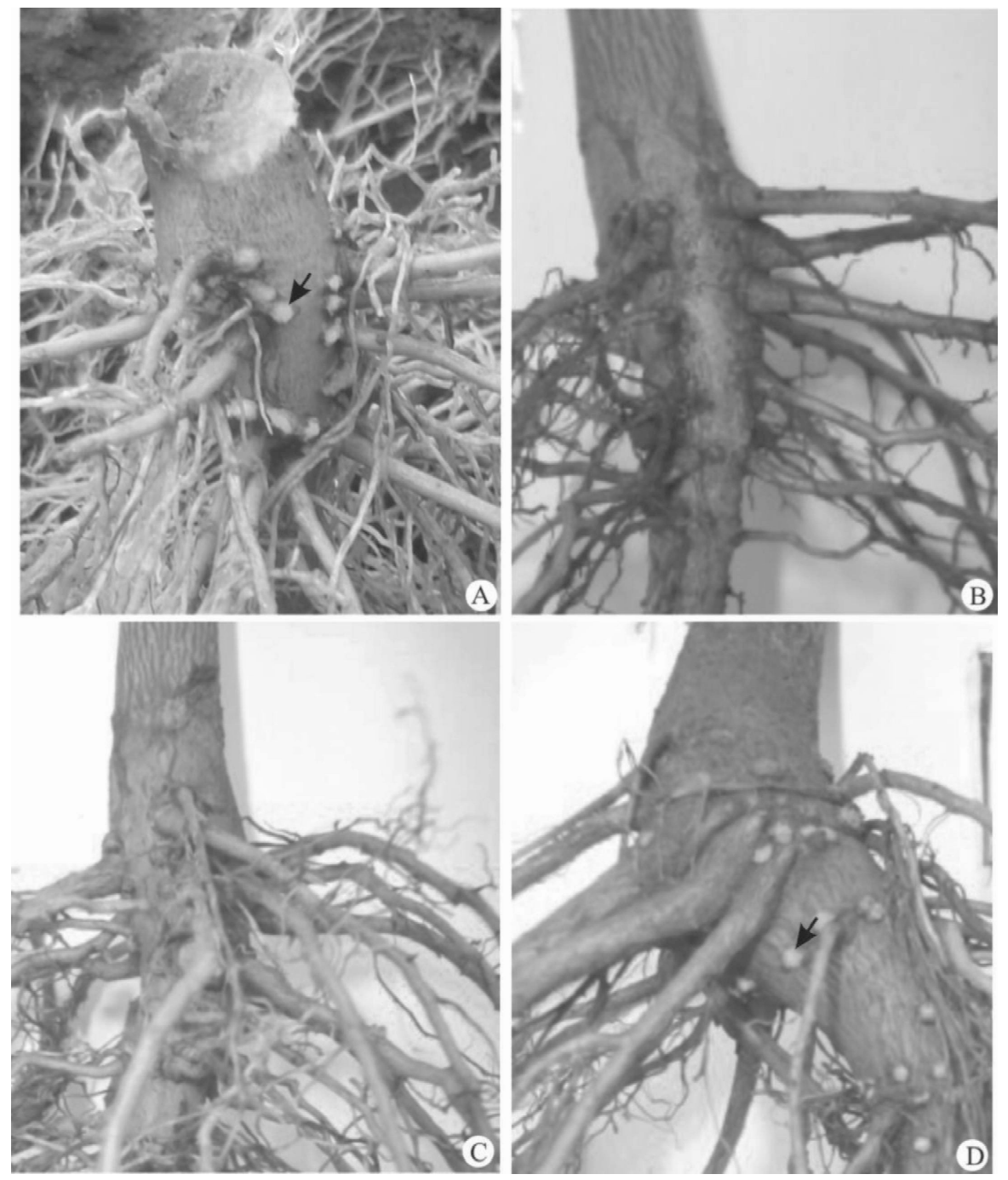

Figura 2 - Alterações morfo-anatômicas em raiz de algodoeiro submetidas a excesso de água. Aparecimento de lenticelas responsáveis pela captação de oxigênio. A. Planta com $100 \%$ do VTP com água com aplicação de Stimulate® na semente, aos 84 dias após semeadura; B. Planta com 25\% do VTP com água, com aplicação de Stimulate® na semente; C. Planta com $60 \%$ do VTP com água com aplicação de Stimulate ${ }^{\circledR}$ na semente ; D. Planta com 100\% do VTP preenchidos com água, com aplicação de Stimulate ${ }^{\circledR}$ na semente, aos 114 dias após semeadura. 
Essa estrutura visa uma maior eficiência na captação de oxigênio, e possivelmente minimizar os danos causados pela ocorrência dos processos fermentativos, decorrentes da falta de oxigênio.

Visualmente, não houve diferença em relação ao aparecimento de lenticelas no sistema radicular do algodoeiro, quando foi aplicado ou não o Stimulate®. Todavia quando as plantas foram submetidas ao excesso de água todas as plantas apresentaram essa modificação morfo-anatômica para uma maior eficiência na captação de oxigênio. Nos demais tratamentos, não foram observadas a formação dessas estruturas (Figura 2 B e C).

$\mathrm{O}$ fato de as condições de excesso de água tornar indisponível o oxigênio para as plantas, faz com que determinadas espécies, quando submetidas a esse tipo de estresse, possam produzir modificações morfo-anatômicas, as quais permitiriam a difusão de oxigênio, mantendo a respiração aeróbica (MEDRI et al., 1998).

O Gossypium hirsutum, cultivar Delta Opal, é uma planta que não tolera déficits hídricos de $25 \%$ VTP iniciando na fase de botão floral, o que compromete o desenvolvimento total da planta e a formação de estruturas reprodutivas, mas tolera o excesso de água de até $100 \%$ do VTP, quando apresenta mudanças nas lenticelas.

O bioestimulante StimulateÒ na dose de $25 \mathrm{ml} \mathrm{500g}$ de sementes e na forma aplicada não proporcionou melhorias ao desenvolvimento das plantas, quando submetidas à deficiência de água.

\section{REFERÊNCIAS BIBLIOGRÁFICAS}

ALMEIDA, O. A.; BELTRÃO, N. E.; GUERRA, H. O. C. Crescimento, desenvolvimento e produção do algodoeiro herbáceo em condições de anoxia do meio edáfico. Pesquisa Agropecuária Brasileira, Brasília, v. 27, n. 9, p. 1259-1272, 1992.

ANTI, G. R.; PERES, L. E. P.; OLIVEIRA, R. F. Estudo dos mecanismos fisiológicos associados à resistência ao déficit hídrico em duas espécies selvagens de Lycopersicon. Horticultura Brasileira, Brasília, v. 20, n. 2, jul. 2002. Suplemento 2.

ARRUDA, F. P.; ANDRADE, A. P.; SILVA, I. F.; PEREIRA, I. E.; GUIMARÃES, M. A. M. Emissão e abscissão de estruturas reprodutivas do algodoeiro herbáceo, cv. CNPA 7H: efeito do estresse hídrico. Revista Brasileira de Engenharia Agrícola e Ambiental, Campina Grande, v. 6, n. 1, p. 21-27, 2002.
AZEVEDO, P. V.; RAO, T. V. R.; ANDRADE NETO, M. S.; PEREIRA, J. R. C.; MACIEL, G. F. Necessidades hídricas da cultura do algodoeiro. Pesquisa Agropecuária Brasileira, Brasília, v. 28, n. 7, p. 863-870, 1993.

BANZATO, D. A.; KRONKA, S. N. Experimentação Agrícola. Jaboticabal: Funep, 1989. 247 p.

BELTRÃO, N. E. M.; AZEVEDO, D. M. P.; NOBREGA, L. B.; SANTOS, J. W. Modificações no crescimento e desenvolvimento do algodoeiro herbáceo sob saturação hídrica do substrato em casa de vegetação. Pesquisa Agropecuária Brasileira, Brasília, v. 32, n. 4, p. 391-397, 1997.

CASTRO, P. R. C.; VIEIRA, E. L. Aplicações de reguladores vegetais na agricultura tropical. Guaíba: Agropecuária, 2001. 132 p.

DOORENBOS, J.; KASSAM, A. H. Efeito da água no rendimento da cultura. Campina Grande: UFPB, 1994. $306 \mathrm{p}$.

EMPRESA BRASILEIRA DE PESQUISA AGROPECUÁRIA. Manual de métodos de análises do solo. 2. ed. Rio de Janeiro: Centro Nacional de Pesquisa de Solos, 1997. 212 p.

KERBAUY, G. B. Fisiologia vegetal. Rio de Janeiro: G. Koogan, 2004. 452 p.

LAMAS, F. M. Reguladores de crescimento. In: EMBRAPAAGROPECUÁRIA OESTE. Algodão: tecnologia de produção. Dourados: Embrapa Algodão, 2001. 296 p.

LARCHER, W. Ecofisiologia vegetal. 2. ed. São Carlos: Rima, 2000. 531 p.

LIMA, M. M.; FARIAS, V. A.; SEVERINO, L. S.; CARDOSO, G. D. Efeito de regulador de crescimento sobre a germinação e desenvolvimento inicial do algodoeiro. In: CONGRESSO BRASILEIRO DE ALGODÃO, 4., 2003, Goiânia, GO. Anais... Goiânia: UFG, 2003. CD-ROM.

MARUR, J. Curvas pressão-volume e expansão foliar em cultivares de algodoeiro submetidos a déficit hídrico.

Revista Scientia Agrícola, Piracicaba, v. 56, n. 3, jul. 1999. 
MCMICHAEL, B. L.; JORDAN, W. R.; POWELL, R. D. An effect of water stress on ethylene production by intact cotton petioles. Plant Physiology, Baltimore, v. 49, p. 658-660, 1973.

MEDRI, M. E.; BIANCHINI, E.; PIMENTA, J. A.; DELGADO, M. F.; CORREA, G. T. Aspectos morfo-anatômicos e fisiológicos de Peltrophorum dubium (Spr.) Taub. submetida ao alagamento e à aplicação de etrel. Revista Brasileira de Botânica, São Paulo, v. 21, n. 3, p. 261-267, 1998.

NAGASHIMA, G.T.; MIGLIORANZA, É.; MARUR, C. J.; YAMAOKA, R.S.; GOMES, J.C. Embebição de sementes e aplicação foliar com cloreto de mepiquat no crescimento e produção do algodoeiro Ciência e Agrotecnologia, Lavras, v.31, n.4, p.1027-1034, jul./ago., 2007.

OOSTERHUIS, D. M. Growth and development of a cotton plant. Faytteville: University of Arkansas Cooperative Extension Service, 1992. 24 p.
PASSOS, S. M. G.; CANÉCHIO, V. F.; JOSÉ, A. Principais culturas. 2. ed. São Paulo: Instituto Campineiro de Ensino Agrícola, 1987. 512 p.

PRADO NETO, M.; DANTAS, A.C.V.L.; VIEIRA, E.L.; ALMEIDA, V. de O. Germinação de sementes de jenipapeiro submetidas à pré-embebição em regulador e estimulante vegetal. Ciência e Agrotecnologia, Lavras, v. 31, n. 3, p. 693-698, maio/jun., 2007.

REICHARDT, K. A água em sistemas agrícolas. São Paulo: Manole, 1990. 186 p.

SANTOS, R. F.; CARLESSO, R. Déficit hídrico e os processos morfológicos e fisiológicos das plantas.

Revista Brasileira de Engenharia Agrícola e Ambiental, Campina Grande, v. 2, n. 3, p. 287-294, 1998.

TAIZ, L.; ZEIGER, E. Fisiologia vegetal. 3. ed. Porto Alegre: Artmed, 2004. 719 p. 